\title{
Design and Fabrication of the Large Thrust Force Piezoelectric Actuator
}

\author{
Shyang-Jye Chang and Jing Chen \\ Department of Mechanical Engineering, National Yunlin University of Science and Technology, EM334B, 123 University Road, \\ Section 3, Douliou, Yunlin 64002, Taiwan
}

Correspondence should be addressed to Shyang-Jye Chang; changjye@yuntech.edu.tw

Received 12 September 2013; Accepted 2 November 2013

Academic Editor: Shoou-Jinn Chang

Copyright (C) 2013 S.-J. Chang and J. Chen. This is an open access article distributed under the Creative Commons Attribution License, which permits unrestricted use, distribution, and reproduction in any medium, provided the original work is properly cited.

\begin{abstract}
This paper presents a novel piezoelectric actuator containing double pushers. By using finite element analysis software, this study simulated the vibration mode and amplitude of piezoelectric actuators. The Taguchi method was used to design the parameters of piezoelectric actuators including length, width, height, and electrodes setting. This paper also presents a discussion regarding the influence that the design parameters had on the actuator amplitudes. Based on optimal design parameters, a novel piezoelectric actuator containing double pushers is produced and some thrust tests are also carried out. From the experiment results, the piezoelectric actuator containing double pushers can provide a greater thrust force than that of traditional actuators containing a single pusher as the preload is greater. Comparing with the traditional actuators, the thrust force of new actuator can be increased by $48 \%$ with the double preload.
\end{abstract}

\section{Introduction}

In 1982, the first piezoelectric actuator was produced by Shinsei. In 1987, piezoelectric actuators were installed in dot matrix printers and mass-produced; this was the first time piezoelectric actuators were used in commercial applications. Canon and Minolta successively applied piezoelectric actuators in the autofocus and shutter units of cameras. In the late 1990s, Toyota used piezoelectric actuators in the automobile industry, specifically in the suspension system and seat adjustment controls of vehicles. In 1995, Epson used piezoelectric actuators to develop print heads in ink-jet printers, thereby beginning the industrial trend of applying piezoelectric actuators in various microsystems [1].

Piezoelectric actuators are categorized into standingwave and traveling-wave actuators according to the drive modes. The vibration mode of traveling-wave actuators is a ripple, which travels in an oval trajectory. The motion trajectories of standing-wave actuators are oval, linear, or of other shapes. The biggest difference between the two types is the wave node, which can be used as a reference when designing fixed points. Traveling-wave actuators do not contain wave nodes, thereby limiting the mechanical design; standing-wave actuators possess wave nodes, which ensure relatively simple designs that are easily miniaturized.

According to the drive signals, piezoelectric actuators are categorized into single-phase [2-5], double-phase [6-9], and multiphase actuators $[5,10-12]$. The motion trajectory of single-phase piezoelectric actuators is nearly linear. Because of a lack of phase differences, single-phase piezoelectric actuators possess a simple driver circuit design and high output efficiency. Double- and multiphase piezoelectric actuators travel in oval trajectories because they are driven by multiple modes. Consequently, the circuit design of these actuators is complex. When two vibration modes are simultaneously excited, differences in frequency tend to prevent effective resonance, thereby lowering efficiency. This setback in doubleand multiphase piezoelectric actuators must be rectified. Based on single-phase standing-wave piezoelectric actuators, this study designed a novel piezoelectric actuator containing double pushers. 


\section{Materials and Methods}

2.1. Concepts. When periodic electrical energy is excited in piezoelectric actuators, periodic deformation occurs. This periodic motion then causes linear or rotational motion in objects because of the friction that pushes or drives objects. Figure 1 presents the driving principles of the vibration mode in an actuator using a single pusher. In traditional designs, vibration modes use single points to produce friction (driving force). Theoretically, if two driving points are used, increased friction can be generated to drive objects, and actuators with greater thrust forces can be designed. The vibration mode of the proposed actuator containing double pushers is shown in Figure 2.

2.2. Parameters Design. Taguchi method is a kind of design of experiment (DOE) developed by Genichi Taguchi. It has been widely used to improve the quality of a product or a manufacturing process by means of statistical method. It usually obtains the optimal design factors by tools such as $S / N$ ratio and orthogonal arrays [13].

In this study, "the average vibration amplitude of two different driving points on the piezoelectric plate" is chosen to be the quality characteristics. The quality characteristic is larger-the-better since the larger vibration amplitude is expected. All possible design factors that affect "the average vibration amplitude of two different driving points on the piezoelectric plate" were considered by a brainstorming in an early design stage. The width of the piezoelectric actuator, the length of the piezoelectric actuator, the thickness of the piezoelectric actuator, and the electrode setting are chosen to be the design factors. The four chosen control factors and their levels for the experiment are shown in Table 1 . An $L_{18}$ array is used to set the parameter optimization experiment levels.

\section{Results and Discussion}

3.1. Simulation Results. Table 2 and Figure 3 are the quality characteristic response table in $X$-direction and the factor effects response plot in $X$-direction, respectively. It is obvious that each factor on the quality characteristics is influential. The order of their contribution is $B>C>A>D$. The biggest vibration amplitude of these two driving points in the $X$ direction will occur with the following combination of factors: $A 2, B 2, C 1$, and $D 3$.

Table 3 and Figure 4 are the quality characteristic response table in $Y$-direction and the factor effects response plot in $Y$-direction, respectively. It is also obvious that each factor on the quality characteristics is influential. The order of their contribution is $B>C>D>A$. The biggest vibration amplitude of these two driving points in the $Y$-direction will occur with the following combination of factors: $A 2, B 2, C 1$, and $D 1$.

Comparing the above results, it is found that the effects of factors $A, B$, and $C$ have good consistency for the $X$-direction or $Y$-direction vibration amplitude. The maximum vibration amplitude of the two driving points on the piezoelectric actuator, both in the $X$-direction and $Y$-direction, occurs
TABLE 1: The control factors and levels table.

\begin{tabular}{lccc}
\hline Factor\level & Level 1 & Level 2 & Level 3 \\
\hline Width $(A)$ & $6 \mathrm{~mm}$ & $8 \mathrm{~mm}$ & \\
Length $(B)$ & $14 \mathrm{~mm}$ & $16 \mathrm{~mm}$ & $18 \mathrm{~mm}$ \\
Thickness $(C)$ & $1 \mathrm{~mm}$ & $1.5 \mathrm{~mm}$ & $2 \mathrm{~mm}$ \\
Electrode setting $(D)$ & $4: 6$ & $5: 5$ & $6: 4$ \\
\hline
\end{tabular}

TABle 2: The quality characteristic response table in $X$-direction (unit: $\mathrm{m}$ ).

\begin{tabular}{lcccc}
\hline & $A$ & $B$ & $C$ & $D$ \\
\hline Level 1 & $3.99 E-8$ & $2.88 E-8$ & $6.97 E-8$ & $4.54 E-8$ \\
Level 2 & $7.10 E-8$ & $8.83 E-8$ & $5.89 E-8$ & $5.53 E-8$ \\
Level 3 & & $4.92 E-8$ & $3.78 E-8$ & $6.56 E-8$ \\
Range & $3.11 E-8$ & $5.95 E-8$ & $3.19 E-8$ & $2.02 E-8$ \\
Rank & 3 & 1 & 2 & 4 \\
\hline
\end{tabular}

TABLE 3: The response table in $Y$-direction (unit: $\mathrm{m}$ ).

\begin{tabular}{lcccc}
\hline & $A$ & $B$ & $C$ & $D$ \\
\hline Level 1 & $6.42 E-8$ & $4.96 E-8$ & $8.80 E-8$ & $7.77 E-8$ \\
Level 2 & $7.32 E-8$ & $8.29 E-8$ & $5.93 E-8$ & $5.90 E-8$ \\
Level 3 & & $7.35 E-8$ & $5.88 E-8$ & $6.93 E-8$ \\
Range & $9.01 E-9$ & $3.34 E-8$ & $2.92 E-8$ & $1.87 E-8$ \\
Rank & 4 & 1 & 2 & 3 \\
\hline
\end{tabular}

as the factors $A, B$, and $C$ are on level 2, level 2, and level 1 , respectively. The maximum vibration amplitude in the $X$-direction of the two driving points on the piezoelectric actuator occurs as the factor $D$ is on level 3. However, the maximum vibration amplitude in the $Y$-direction of the two driving points on the piezoelectric actuator occurs as the factor $D$ is on level 1. Comparing the effects response of factor $D$ in Figure 4, the factor effects response is quite close when the factor $D$ is on level 1 or level 3. Therefore, the factors and settings of $A 2$ (width $=8 \mathrm{~mm}$ ), $B 2$ (length $=16 \mathrm{~mm}$ ), $C 1$ (thickness $=1 \mathrm{~mm}$ ), and D3 (electrode setting $=6: 4$ ) are chosen to be the optimal parameters combination.

3.2. Fabrication and Measurements. The pushers should be set at the positions with maximum amplitude on the piezoelectric actuator to produce the larger thrust force. The fixtures should be set at the positions with minimum amplitude on the piezoelectric actuator so as not to affect the operation of the actuator. Figure 5 is the vibrating amplitudes in the $X$-direction and the $Y$-direction along the length of piezoelectric actuator. Seeking these two curves in Figure 5, it can be found that the maximum amplitudes, both in the $X$-direction and the $Y$-direction, of the piezoelectric actuator occur at the positions of $6 \mathrm{~mm}$ and $10 \mathrm{~mm}$. Therefore, the two pushers are set at these positions. The minimum amplitudes, both in the $X$-direction and the $Y$-direction, of the piezoelectric actuator occur at the positions of $3 \mathrm{~mm}$ and $13 \mathrm{~mm}$. Therefore, the two fixtures are set at these positions. Figure 6 shows the detailed dimensions of the large thrust force piezoelectric actuator with double pushers. 


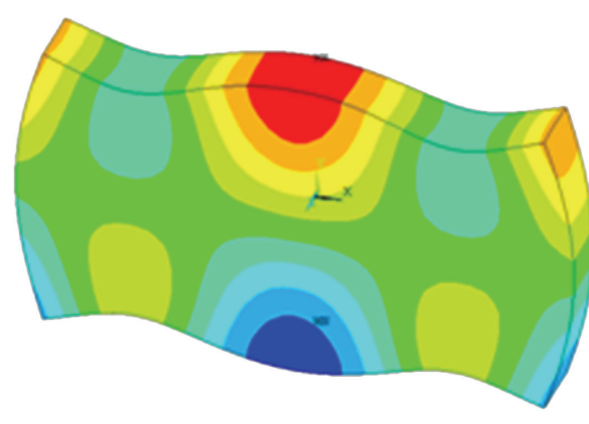

(a)

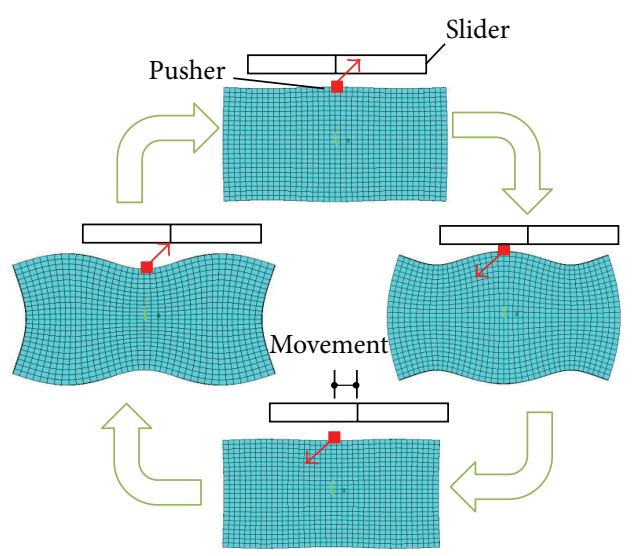

(b)

FIGURE 1: (a) Vibration mode of actuator using a single pusher. (b) Driving principles of the actuator.

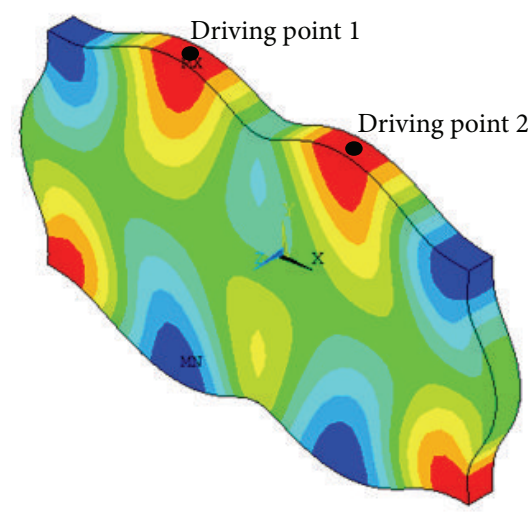

FIGURE 2: Vibration mode of actuator using double pushers.

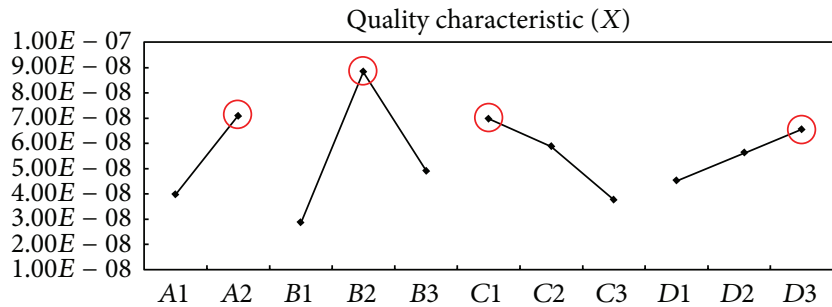

Figure 3: The factor effects response plot in $X$-direction.

In order to measure the output thrust force of the piezoelectric actuator containing double pushers, this actuator is used in the linear stage. Figure 7 is linear stage using the large thrust force piezoelectric actuator. The linear stage includes a large thrust force piezoelectric actuator, a miniature linear guide, a uniaxial load-cell, a set of preload mechanism, and an adjusting screw. The pushers contact with the carriage on the linear guide. The preload mechanism is set on the other side and contacts with the fixtures on the piezoelectric actuator. By adjusting the screw, the preload mechanism will push the piezoelectric actuator toward the direction of linear guide to produce a proper preload between the pushers and

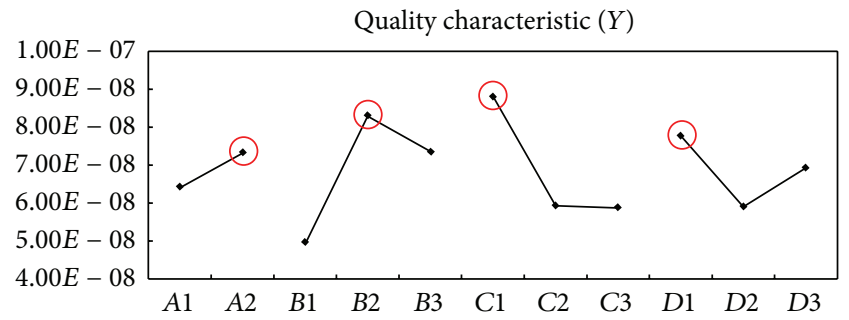

FIGURE 4: The factor effects response plot in $Y$-direction.

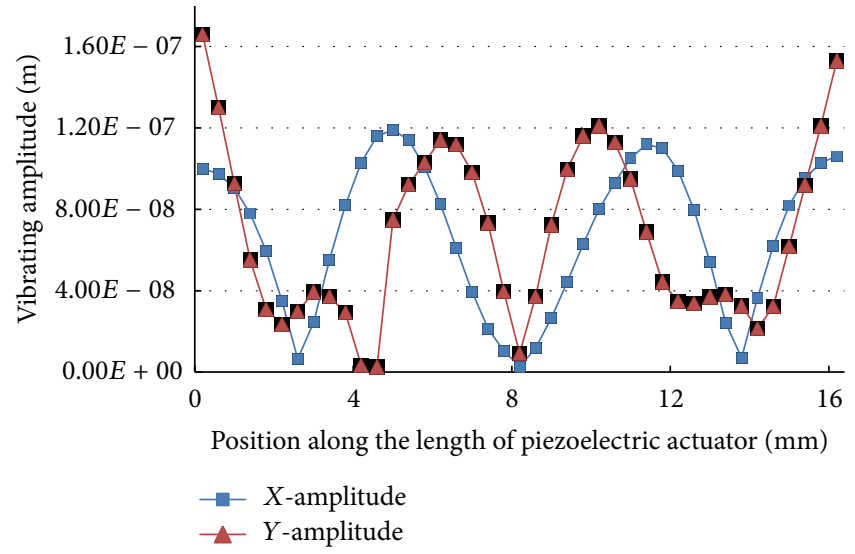

FIgure 5: The vibrating amplitudes in the $X$-direction and the $Y$ direction along the length of piezoelectric plate.

the carriage on the linear guide. The preload can be measured by the load-cell.

In this study, the thrusts force of novel piezoelectric actuator containing double pushers and the conventional piezoelectric actuator containing a single pusher are measured. The setup of thrust force measurement experiment is shown in Figure 8. The drive signal generated by a function generator is supplied to the piezoelectric actuator through a power amplifier and an oscilloscope is used to monitor the drive signal. A force gauge is used to measure the thrust force 


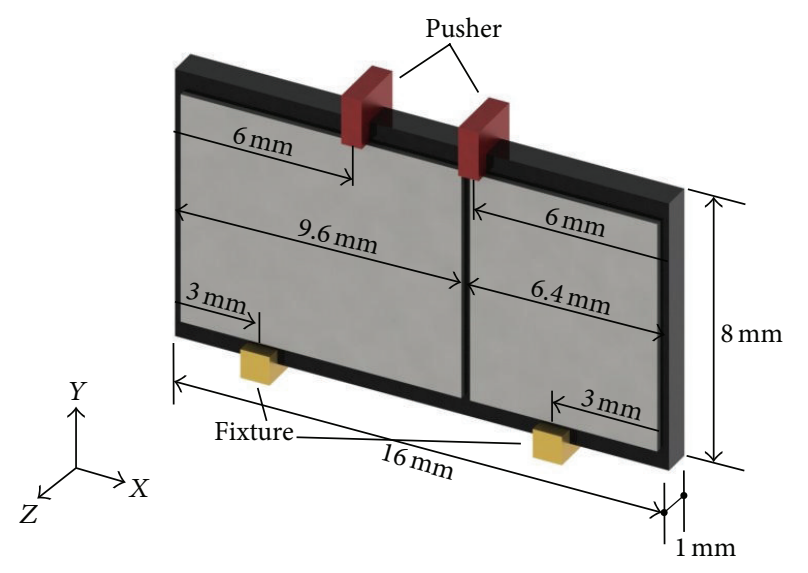

FIgURE 6: The detailed dimensions of the large thrust piezoelectric actuator.

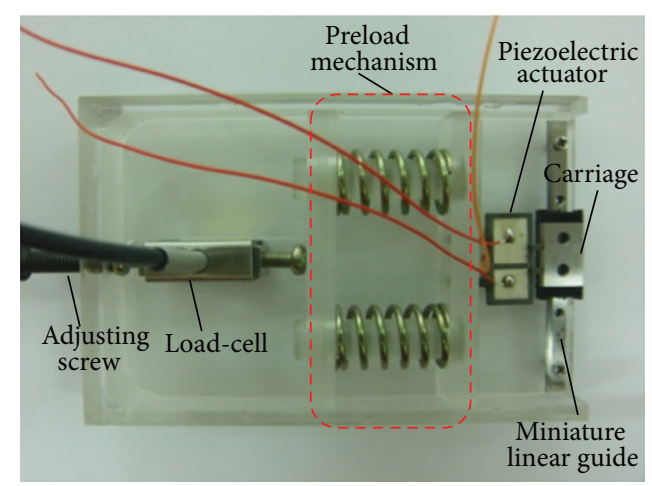

Figure 7: The linear stage using the large thrust piezoelectric actuator.

of the linear stage as the piezoelectric actuator is excited. Figure 9 shows the thrust measurement experiment.

The resonance frequency of piezoelectric actuator containing one single pusher obtained by simulation is about $222 \mathrm{kHz}$. The actual operating frequency is about $218 \mathrm{kHz}$ after the actuator is assembled in the linear stage. After initial testing, the appropriate preload of $215 \mathrm{~g}$ is chosen. Too large or small preload will influence the normal operating of the actuator. The thrusts forces of the linear stage with the preload of $215 \mathrm{~g}$ and the drive voltage $30 \mathrm{Vpp}$ are shown in Table 4 . The average thrust force is about $70 \mathrm{~g}$ as the operating frequency is $218 \mathrm{~Hz}$.

The resonance frequency of piezoelectric actuator containing double pushers obtained by simulation is about $261 \mathrm{kHz}$. The actual operating frequency is about $256 \mathrm{kHz}$ after the actuator is assembled in the linear stage. The thrusts forces of the linear stage with the preload of $215 \mathrm{~g}$ and the drive voltage $30 \mathrm{Vpp}$ are shown in Table 5. The average thrust force is about $60 \mathrm{~g}$ as the operating frequency is $256 \mathrm{~Hz}$. The performance is worse than the thrust force of piezoelectric actuator containing one single pusher.

The thrust force will be affected because the preload varies since the linear stage is driven via a friction between the pushers and the carriage. Therefore, the measurement experiment

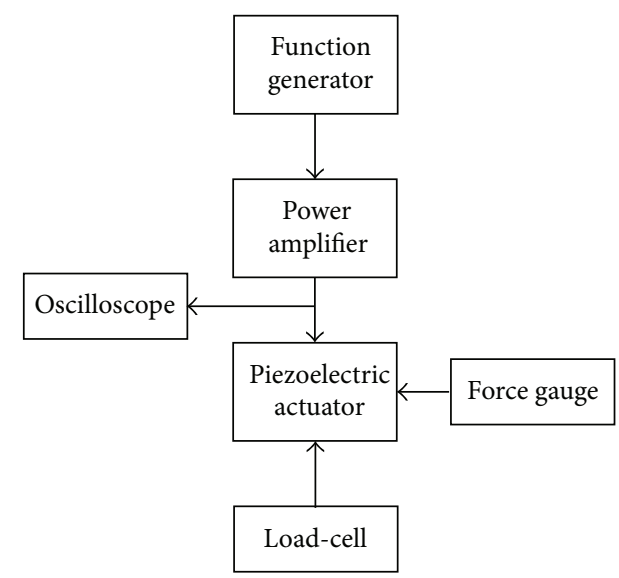

Figure 8: Setup of thrust measurement experiment.

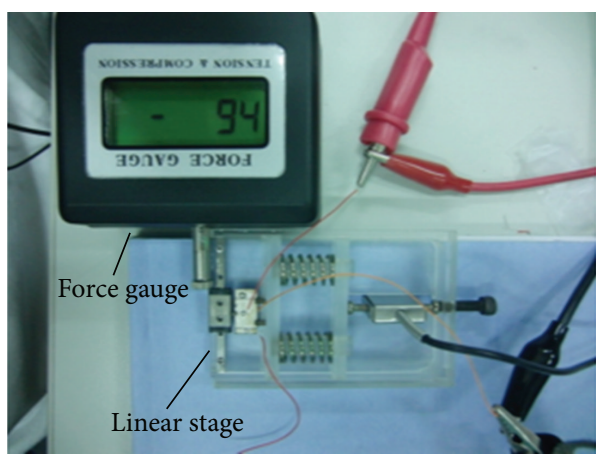

Figure 9: Thrust measurement experiment.

TABLE 4: Thrusts of piezoelectric actuator containing single pusher (preload of $215 \mathrm{~g}$, drive voltage $30 \mathrm{Vpp}$ ).

\begin{tabular}{lcccccc}
\hline $\begin{array}{l}\text { Freq. } \\
(\mathrm{kHz})\end{array}$ & $\begin{array}{c}\text { Test } 1 \\
(\mathrm{~g})\end{array}$ & $\begin{array}{c}\text { Test 2 } \\
(\mathrm{g})\end{array}$ & $\begin{array}{c}\text { Test 3 } \\
(\mathrm{g})\end{array}$ & $\begin{array}{c}\text { Test 4 } \\
(\mathrm{g})\end{array}$ & $\begin{array}{c}\text { Test } 5 \\
(\mathrm{~g})\end{array}$ & $\begin{array}{c}\text { Ave. } \\
\text { thrust } \\
(\mathrm{g})\end{array}$ \\
\hline 217 & 60 & 62 & 69 & 63 & 57 & 62.2 \\
218 & 64 & 68 & 72 & 73 & 70 & 69.4 \\
219 & 54 & 57 & 60 & 52 & 55 & 55.6 \\
\hline
\end{tabular}

TABLE 5: Thrusts of piezoelectric actuator containing double pushers (preload of $215 \mathrm{~g}$, drive voltage $30 \mathrm{Vpp}$ ).

\begin{tabular}{lcccccc}
\hline $\begin{array}{l}\text { Freq. } \\
(\mathrm{kHz})\end{array}$ & $\begin{array}{c}\text { Test 1 } \\
(\mathrm{g})\end{array}$ & $\begin{array}{c}\text { Test 2 } \\
(\mathrm{g})\end{array}$ & $\begin{array}{c}\text { Test 3 } \\
(\mathrm{g})\end{array}$ & $\begin{array}{c}\text { Test 4 } \\
(\mathrm{g})\end{array}$ & $\begin{array}{c}\text { Test } 5 \\
(\mathrm{~g})\end{array}$ & $\begin{array}{c}\text { Ave. } \\
\text { thrust } \\
(\mathrm{g})\end{array}$ \\
\hline 255 & 51 & 52 & 54 & 49 & 50 & 51.2 \\
256 & 61 & 62 & 57 & 58 & 59 & 59.4 \\
257 & 55 & 54 & 58 & 57 & 56 & 56.0 \\
\hline
\end{tabular}

was carried out again with the preload of $430 \mathrm{~g}$. The thrusts of the linear stage are shown in Table 6. The average thrust force is about $103 \mathrm{~g}$ as the operating frequency is $256 \mathrm{~Hz}$ which is better than the thrust force of piezoelectric actuator containing one single pusher. From the above experimental 
TABLE 6: Thrusts of piezoelectric actuator containing double pushers (preload of $430 \mathrm{~g}$, drive voltage $30 \mathrm{Vpp}$ ).

\begin{tabular}{lcccccc}
\hline $\begin{array}{l}\text { Freq. } \\
(\mathrm{kHz})\end{array}$ & $\begin{array}{c}\text { Test } 1 \\
(\mathrm{~g})\end{array}$ & $\begin{array}{c}\text { Test } 2 \\
(\mathrm{~g})\end{array}$ & $\begin{array}{c}\text { Test 3 } \\
(\mathrm{g})\end{array}$ & $\begin{array}{c}\text { Test 4 } \\
(\mathrm{g})\end{array}$ & $\begin{array}{c}\text { Test 5 } \\
(\mathrm{g})\end{array}$ & $\begin{array}{c}\text { Ave. } \\
\text { thrust } \\
(\mathrm{g})\end{array}$ \\
\hline 255 & 100 & 105 & 95 & 94 & 98 & 98.4 \\
256 & 98 & 99 & 109 & 103 & 106 & 103.0 \\
257 & 90 & 95 & 98 & 97 & 95 & 95.0 \\
\hline
\end{tabular}

results, it is found that the piezoelectric actuator containing double pushers can provide a larger thrust as the preload is greater.

\section{Conclusions}

This study presents a novel piezoelectric actuator. The double pushers on the piezoelectric actuator are designed to enhance the thrust output. In the design process, Taguchi method is used to find the optimal combination of parameters including length, width, height, and electrodes setting. The contribution of each design factor of piezoelectric actuator is also discussed in this paper. Furthermore, a novel piezoelectric actuator containing double pushers according to the optimal design factors is produced and used in a linear stage. Some thrust tests are also carried out in this study. From the experiment results, the piezoelectric actuator containing double pushers can provide a greater thrust force than that of traditional actuators containing a single pusher as the preload is greater. Compared with the traditional actuators, the thrust force of new actuator can be increased by $48 \%$ with the double preload.

\section{Conflict of Interests}

The authors declare that there is no conflict of interests regarding the publication of this paper.

\section{Acknowledgment}

The authors would like to thank National Science Council (NSC) for their financial supports to the project (Grant no. NSC 101-2221-E-224-009).

\section{References}

[1] K. Uchino, "Piezoelectric actuators 2006: expansion from IT/robotics to ecological/energy applications," Journal of Electroceramics, vol. 20, no. 3-4, pp. 301-311, 2008.

[2] O. Vyshnevskyy, S. Kovalev, and W. Wischnewskiy, "A novel, single-mode piezoceramic plate actuator for ultrasonic linear motors," IEEE Transactions on Ultrasonics, Ferroelectrics, and Frequency Control, vol. 52, no. 11, pp. 2047-2053, 2005.

[3] K. Otokawa, K. Takemura, and T. Maeno, "A multi-degree-offreedom ultrasonic motor using single-phase-driven vibrators," in Proceedings of the IEEE IRS/RSJ International Conference on Intelligent Robots and Systems (IROS '05), pp. 499-504, August 2005.
[4] S.-B. Lee, T. S. Key, Z. Liang et al., "Microstructure design of lead-free piezoelectric ceramics," Journal of the European Ceramic Society, vol. 33, pp. 313-326, 2013.

[5] S. C. Shen, P. C. Tsai, Y.-J. Wang, and H. J. Huang, "A new type of multi-degree-of-freedom miniaturization actuator using symmetric piezoelectric pusher element for a pocket suntracking system," Snesors and Actuator A, vol. 182, pp. 114-121, 2012.

[6] T. Takano, Y. Tomikawa, M. Aoyagi, T. Ogasawara, and A. Yabuki, "Ultrasonic linear motors for application to driving a light pick-up element," in Proceedings of the IEEE Ultrasonics Symposium, pp. 445-448, November 1993.

[7] W.-H. Lee, C.-Y. Kang, D.-S. Paik, B.-K. Ju, and S.-J. Yoon, "Butterfly-shaped ultra slim piezoelectric ultrasonic linear motor," Sensors and Actuators A, vol. 168, no. 1, pp. 127-130, 2011.

[8] S. T. Ho, "Characteristics of the linear ultrasonic motor using an elliptical shape stator," Japanese Journal of Applied Physics, vol. 45, no. 7, pp. 6011-6013, 2006.

[9] C. Lu, T. Xie, T. Zhou, and Y. Chen, "Study of a new type linear ultrasonic motor with double-driving feet," Ultrasonics, vol. 44, pp. e585-e589, 2006.

[10] M. Aoyagi, Y. Tomikawa, and T. Takano, "Ultrasonic motors using longitudinal and bending multimode vibrators with mode coupling by externally additional asymmetry or internal nonlinearity," Japanese Journal of Applied Physics, vol. 31, no. 9, pp. 3077-3080, 1992.

[11] J. Friend, A. Umeshima, T. Ishii, K. Naktaro, and S. Ueha, "A piezoelectric linear actuator formed from a multitude of bimorphs," Sensors and Actuators A, vol. 109, no. 3, pp. 242-251, 2004.

[12] S.-W. Hsiao and M.-C. Tsai, "Design of a novel piezoelectric vibrator driven by asymmetrical electric fields for linear ultrasonic motors," Journal of the Chinese Society of Mechanical Engineers, vol. 32, no. 2, pp. 111-117, 2011.

[13] H.-L. Lee, S.-J. Chang, S.-J. Hwang, F. Su, and S. K. Chen, "Computer-aided design of a TSOP II LOC package using Taguchi's parameter design method to optimize mold-flow balance," ASME Journal of Electronic Packaging, vol. 125, no. 2, pp. 268-275, 2003. 

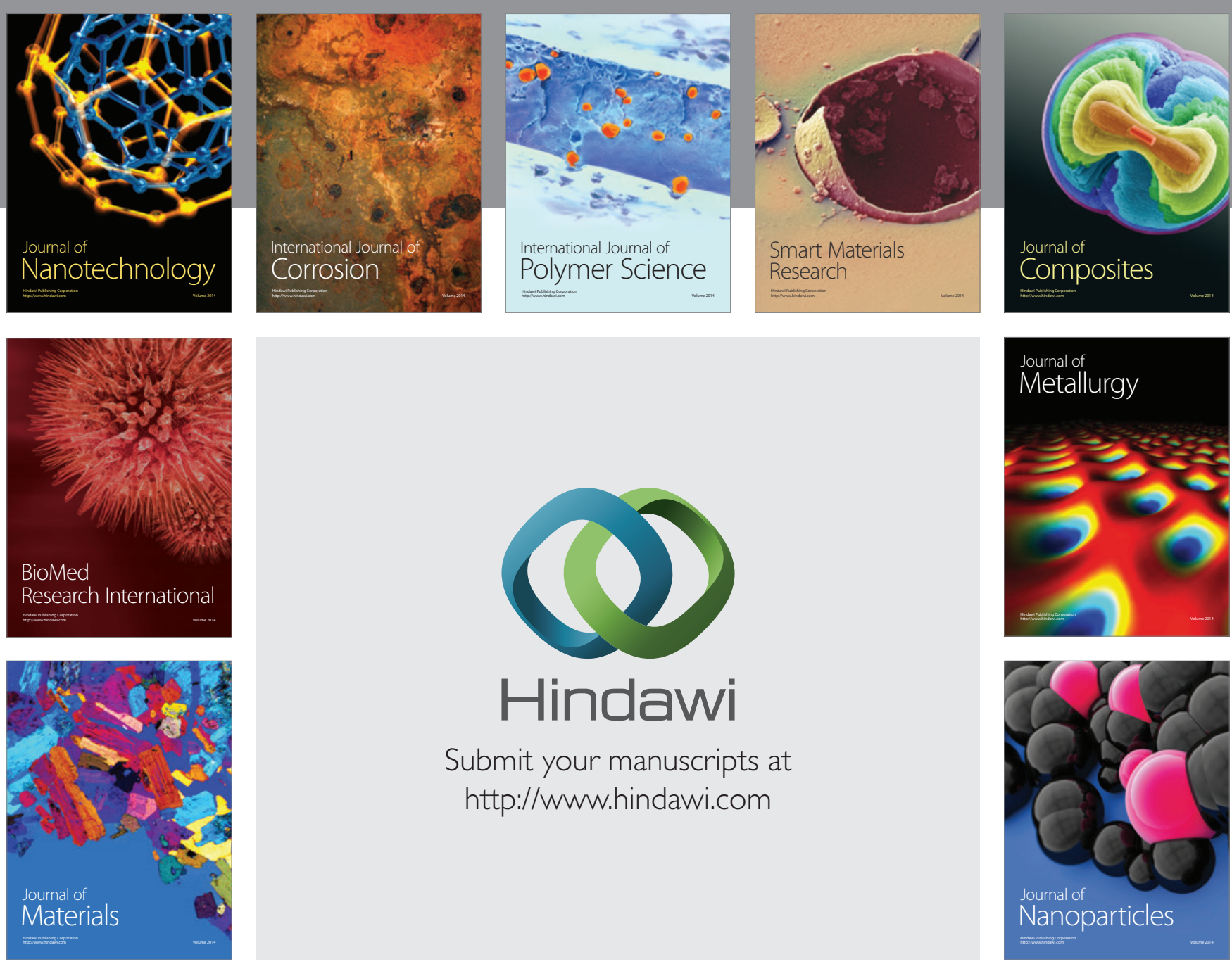

Submit your manuscripts at http://www.hindawi.com
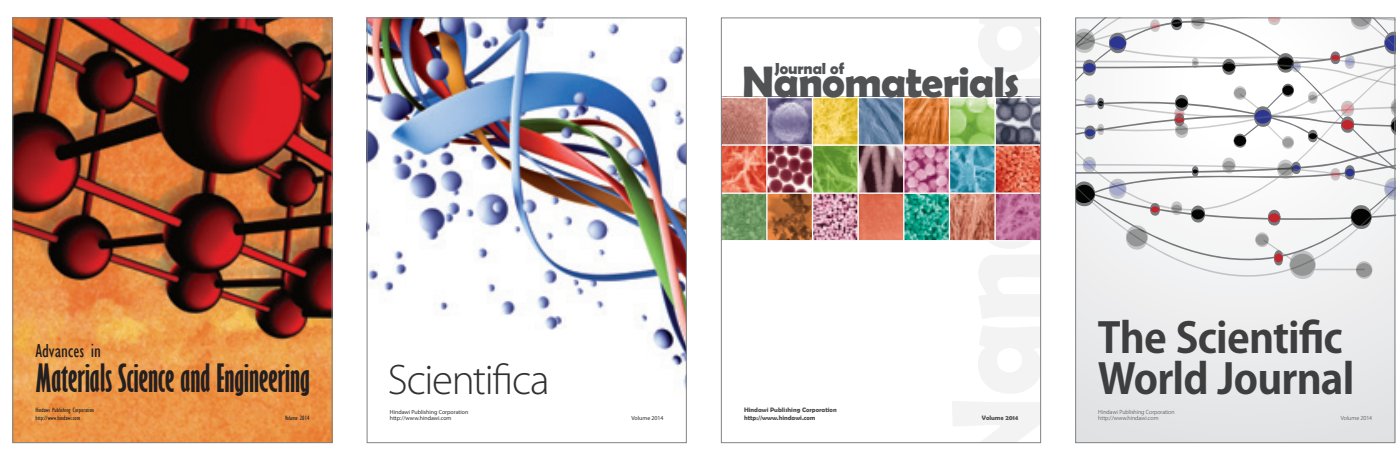

\section{The Scientific World Journal}
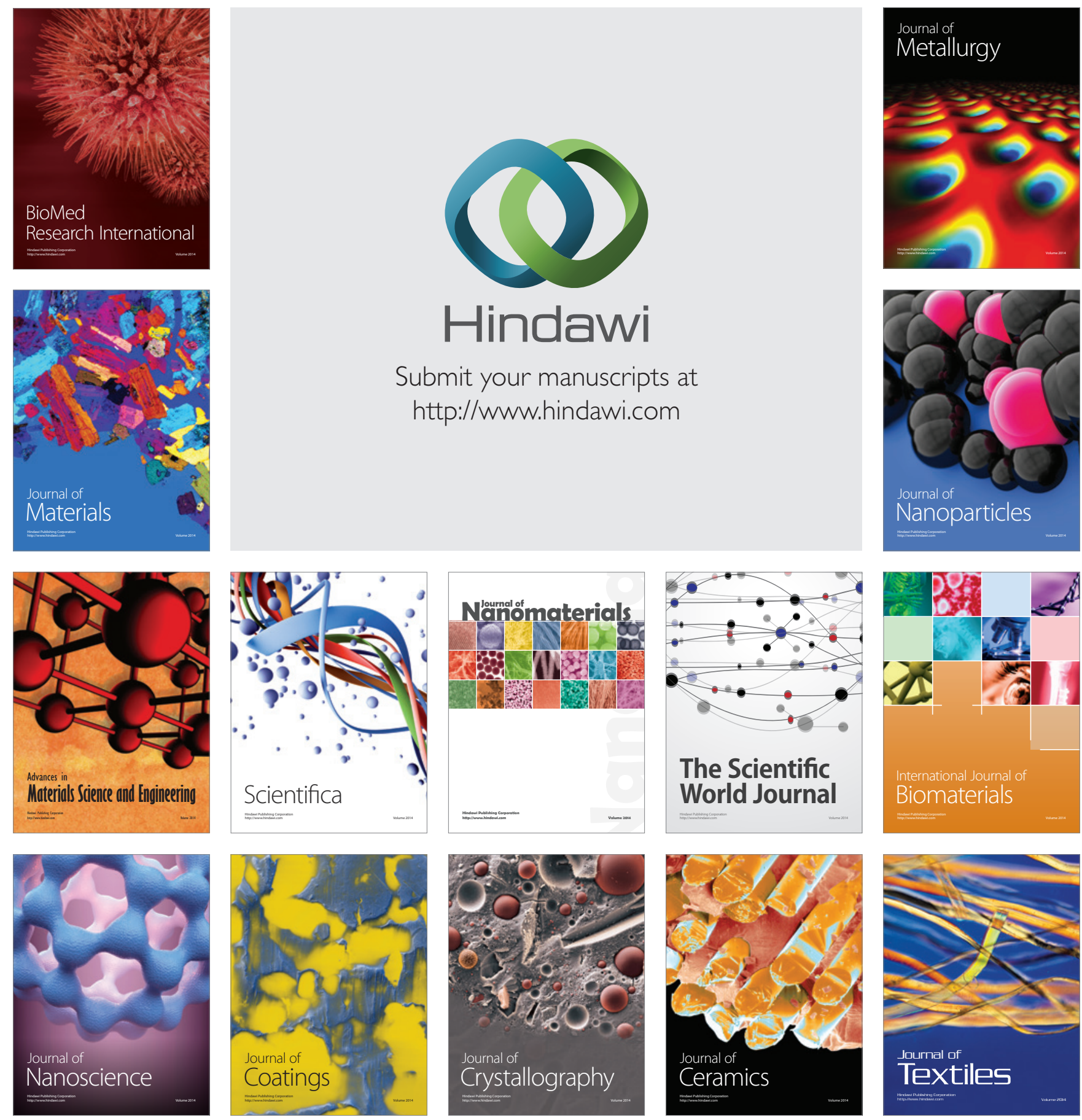